and self-confidence as a lifelong learner if they are to contribute effectively to continuously improving practice. ${ }^{13}$ If their learning about improvement does not achieve this, it will soon become a distant although interesting memory as they cope with the stresses and turbulence of everyday work. The use of "active learning" by Kyrkjebø et al" is an important attempt to address this need and gives us clues about creating opportunities for practice based learning in mainstream education.

Their work raises many challenges of implementation for both education and service providers. With regard to the former, there is a particular need to develop the interest and skills of the academic staff who must themselves gain experience of facilitating improvement projects in practice. Unless they do so they will never be able to underpin their teaching with the personal feeling that is critical for helping students to learn. ${ }^{14}$ With regard to service providers, Kyrkjebø et al express the hope that their students' experience "will enable them to take part actively in quality improvement when they are qualified". This is unlikely to happen by chance and raises significant questions about the environments in which students must learn and will have to practise. ${ }^{7}$ In particular, practice based learning requires the creation of opportunities for students to participate in work settings where clinical teams are using systematic approaches to improve their care as part of their everyday work. After qualifying, they require opportunities to develop themselves and their improvement skills within routine organisational staff development programmes. Continuous improvement needs to be integral to both educational and healthcare institutions.

The final message that can be taken from the paper by Kyrkjebø et al is perhaps the most profound. Integrating our basic human enjoyment of learning with deep feelings about providing the best possible care for our patients provides an enormously powerful driver for improvement. It creates the demand for health profession educators and service providers to understand that they are part of the same system of care delivery with a shared underlying purpose. Put another way, how can we provide services that continuously improve care and education at the same time? This requires a sophisticated dialogue between employers and academics that will establish partnerships between healthcare providers and higher education and will provide benefits for learners, providers, and the wider community. ${ }^{13}$

P WILCOCK

E CARR

Institute of Health and Community Studies,

Bournemouth University,

Bournemouth

Dorset BH1 3LT, UK

PeterWilcock@compuserve.com

1 Cox S, Wilcock P, Young J. Improving the repeat prescribing process in a busy general practice: a study using continuous quality improvement methodology. Quality in Health Care 1999;8:119-25.

2 Headrick L, Katcher W, Neuhauser D, et al. Continuous quality improvement and knowledge applied to asthma care. ft Comm $\mathcal{F}$ Qual Improv 1994;20:562-8.

3 Weeks WB, Mills PD, Dittus RS, et al. Using an improvement model to reduce adverse events in VA facilities. Ft Comm $\mathcal{f}$ Qual Improv 2001;27:243-54

4 Department of Health. Redesign: a toolkit. Service improvement guide. London: The Modernisation Agency, 2001.

5 Geboers H. Implementing continuous quality improvement in general practice: the whole package or a series of projects. Quality in Health Care 1999;8:77

6 Batalden PB, Stoltz PK. A framework for the continual improvement of healthcare: building and applying professional and improvement knowledge to test changes in daily work. Ft Comm f Oual Improv 1993;19:424-52.

7 Kyrkjebø JM, Hanssen TA, Haugland BØ. Introducing quality improvement to pre-qualification nursing students: an evaluation of an experiential proto pre-qualification nursing students: an evaluation

8 Headrick LA, Knapp M, Neuhauser D, et al. Working from upstream to improve health care: the IHI Interdisciplinary Education Collaborative. $\mathfrak{f t}$ Comm f Qual Improv 1996;22:149-63.

9 Headrick LA, Wilcock PW, Batalden PB. Interprofessional working and continuing medical education. BMF 1998;316:771-4.

10 Annandale SJ, McCann S, Nattrass H, et al. Achieving health improvements through interprofessional learning in South West England. F Interprofessional Care 2000;14:161-74.

11 Chessman AW, Bellack JP, Lahoz MR, et al. Students add value to learning organisations: the Medical University of South Carolina experience. Qual Manag Health Care 1998;6:38-43.

12 Marton F, Saljo R. On qualitative differences in learning: I. Outcome and process. Br $\mathcal{F}$ Educ Psychol 1976;46:4-11.

13 Knapper C. Approaches to study and lifelong learning: some Canadian initiatives. In: Gibbs G, ed. Improving student learning - through assessment and evaluation. Oxford: Oxford Centre for Staff Development, 1994.

14 Palmer PJ. The courage to teach. San Francisco: Jossey-Bass, 1998.

\title{
Guidelines, judgement, opinion, and clinical experience
}

Over the past decade it has become a commonplacealmost a definitional truism - to subscribe to the Institute of Medicine's view that clinical guidelines are (or should be) "systematically developed statements which assist practitioner and patient decisions about appropriate health care". ${ }^{1}$ Guidelines now subserve other functions too: they provide up to date overviews of research evidence, its strengths, weaknesses and scope of application; summarise research findings in a manner which allows derivation of performance indicators and review criteria; and are used to develop pathways of care, reminder prompts, and to help set healthcare priorities. Indeed, one influential researcher notes that, although guidelines may once have been intended "to be aids to decision making by patients and practitioners ... we do not use them in this way. Instead, they are used to modify the clinical behaviours of practitioners and reduce inappropriate variations in care". ${ }^{2}$

It is conventional wisdom that the development and application of guidelines are especially appropriate in situations where clinicians are uncertain what-if anything-is the most effective way of treating a particular clinical problem and where there exists reliable scientific evidence which, properly interpreted, can offer a sound basis for developing guidance. Reliable interpretation of scientific evidence is dependent on the adoption of formal methods to inform guideline development and encompasses:

- an explicit approach to identifying areas of practice where guidelines could prove helpful;

- convening competent guideline development groups;

- retrieval, assessment, and synthesis of all relevant evidence to the clinical area addressed;

- translation of evidence into clinical recommendations;

- external review of guideline recommendations..$^{3-6}$

Since guidelines offer explicit recommendations with the definite intent of influencing what clinicians $d o$, their clinical recommendations make claims which range beyond those which can be derived logically from the results of meta-analyses or randomised trials. The clinical scope of level I evidence is generally too narrow to allow clinically useful guidelines to be created from these sources alone, so recommendations require moorings to other evidential findings and information, including expert and consensus 
opinion. Guideline formulation thereby steps beyond the results of particular studies and beyond re-presentations of published systematic evidence to incorporate processes of judicious extrapolation, interpretation, and value judgement. $^{7}$

The paper by Rycroft-Malone ${ }^{8}$ in this issue of Quality in Health Care illustrates how guideline developers can bring rigorous techniques to bear in tackling such tasks. In the context of an evidence-linked guideline development process, she describes the formal means adopted by the Royal College of Nursing Institute's Quality Improvement Programme to develop a national guideline on assessment of risk and prevention of pressure ulcers. Ulcer risk assessment is a complex clinical area in which explicit evidence relating to a wide range of problems and techniques has been summarised..$^{9-11}$ From these summaries, 200 statements were derived and rated on a "disagree/agree" scale of 1-9 by 10 members of a panel composed of participants who reflected the range of people to whom the guideline would apply. The panel was sent summaries of the research evidence and was asked to rate each recommendation statement, taking account of the evidence, their own expertise, and the opinions and realities of healthcare provision in the UK. The results of this exercise were fed back to panel members by the guideline developers, and the panel considered again each statement with particular focus on those that had caused most disagreement. The threshold score for incorporation of each recommendation into the guideline was set at a median score of 7 or above, and an indication of the degree of agreement dispersion across the median score was included. A total of 160 recommendations were thereby adopted in the final guideline, which comprises a mixture of research based and consensus based recommendations. One wonders how many more would have been removed from the guideline had the median score been set at 7.5 or 8.5 , or if a qualifying narrow interquartile range had been set to guarantee a minimum level of agreement.

The transparent approach of the Royal College of Nursing Institute to the development of a national guideline on assessment of risk and prevention of pressure ulcers goes some way towards reassuring those who for some time have warned of the dangers of treating guidelines as pronouncements which carry oracular authority. Ten years ago, for example, Tong wrote: "Medical practitioners should regard the recommendations of consensus development conferences as useful reference tools: not the rulings of philosopher kings, but the attempt of thoughtful people to share their knowledge-albeit imperfect-with other people". ${ }^{12}$

Formal techniques for appraising the results and relevance of scientific studies and of systematic reviews are now relatively well established in the context of guideline development. ${ }^{13}$ The report by Rycroft-Malone offers an approach which also brings rigour and stringency to the equally important task of assaying diverse sources of judgement, expert opinion, and clinical experience in their construction.

B HURWITZ

Head, Department of Primary Health Care and General Practice,

Centre for Primary Care and Social Medicine,

Faculty of Medicine, Charing Cross Campus,

London W6 8RP, UK

b.hurwitz@ic.ac.uk

1 Field MJ, Lohr KN, eds. Clinical practice guidelines: directions for a new program. Institute of Medicine, Committee to Advise the Public Health Service on Clinical Practice Guidelines. Washington, DC: National Academy Press, 1990.

2 Baker R. Is it time to review the idea of compliance with guidelines? $\mathrm{Br} \mathcal{F} \mathrm{Gen}$ Pract 2001;51:7.

3 Eccles M, Mason J. How to develop cost-conscious guidelines. Health Technol Assess 2001;5(16).

4 Shekelle P, Woolf S, Eccles M, et al. Developing guidelines. In: Eccles M, Grimshaw J, eds. Clinical guidelines: from conception to use. Oxford: Radcliffe Medical Press, 2000: 49-67.

5 Grimshaw JM, Freemantle N, Wallace S, et al. Development and implementation of clinical practice guidelines. Quality Health Care 1995;4:55-66.

6 Whitty $\mathrm{P}$, Eccles $\mathrm{M}$, Woolf $\mathrm{SH}$, et al. Using and developing clinical guidelines. In: Jones R, Britten N, Culpepper L, et al, eds. The Oxford textbook of primary care. Oxford: Oxford University Press, 2001 (in press).

7 Hurwitz B. Clinical guidelines and the law: negligence, discretion and judgment. Oxford: Radcliffe Medical Press, 1998.

8 Rycroft-Malone J. Formal consensus: the development of a national clinical guideline. Quality Health Care 2001;10:238-44.

9 Agency for Health Care Policy and Planning. Pressure ulcers in adults: prediction and prevention. Clinical Practice Guideline Number 3. Maryland: US Department of Health and Human Sciences, 1992.

10 NHS Centre for Reviews and Dissemination. The prevention and treatment of pressure sores. Effective Health Care Bulletin 1995;2(1).

11 Cullumn N, Deeks J, Sheldon TA, et al. Beds, mattresses and cushions for preventing pressure sores. In: The Cochrane Library. Issue 1. Oxford: Update Software, 2000.

12 Tong R. The epistemology and ethics of consensus: uses and misuses of 'ethical' expertise. F Med Philosophy 1991;16:409-26.

13 Eccles M, Grimshaw J, eds. Clinical guidelines: from conception to use. Oxford: Radcliffe Medical Press, 2000. 